\title{
ASSOCIATION OF DIETARY PATTERNS WITH SOME RISK BIOMARKERS OF CHRONIC KIDNEY DISEASE OF SAUDI PATIENTS
}

\author{
Fathia Khogali*
}

*Umm Al-Qura University

\section{*Corresponding Author: -}

\begin{abstract}
: -
Chronic kidney disease (CKD) is a worldwide public health problem. There has been a marked rise in the prevalence of $(C K D)$ in Saudi Arabia. This study aimed to identify dietary pattern of Saudi CKD patients and to evaluate the relationship between dietary patterns and the biomarkers in CKD. The study was conducted among 58 previously diagnosed with $C K D$, both genders, aged $>70$ years. Information regarding dietary patterns, demographic and medical history variables was obtained with an online questionnaire. Four dietary patterns, were identified, explaining $54.06 \%$ of the variance; Veggie Dietary Pattern, Plant-based Dietary Pattern, Miscellanies Pattern, and Animal-based Dietary Pattern. Correlation between dietary patterns and the metabolic risk factors of CKD; glomerular filtration rate (G3a, G3b), Serum creatinine, and albumin/creatinine ratio, showed inverse significant association with Veggie Dietary Pattern and the metabolic risk factors ( $r-0.591 P .008, r-0.574$ P.015, $r-607$ P.007, $r$-.601P.007) respectively. while Animal-based Dietary Pattern was most closely associated with metabolic risk factors (r.557 P.021, r.551 P.023, r.661, P.001, r.660 $P .001)$ respectively. Marginally significant association was found between Plant-based Dietary Pattern and Miscellanies Pattern with CKD complications.

After adjustment for age, gender, and BMI same correlation still found.
\end{abstract}

Key words: Dietary pattern. Chronic kidney disease. glomerular filtration rate. Serum creatinine. albumin/creatinine ratio 


\section{INTRODUCTION}

Chronic kidney disease has a high global prevalence between 11 to $13 \%$ with the majority stage 3 (1). CKD can lead to conditions such as cardiovascular diseases and endstage renal disease (2). There has been a marked rise in the prevalence and incidence of (CKD) in Saudi Arabia due to massive urbanization that has occurred over the last 2 decades (3). Proper dietary management may help to slow the progression of kidney disease. Studies showed that food patterns may have stronger effects on health than any single component (4).

This study was designed to assess the dietary patterns and their associations with biomarkers of patients with (CKD) at the pre-dialysis stage.

\section{Materials and Methods}

\subsection{Participants:}

The study recruited outpatients who consecutively attended hospitals in Makkha area. For participation in the study, the inclusion criteria specified were; diagnosis of chronic kidney disease (CKD) with glomerular filtration rate (GFR) of Stage 3 (G3a, G3b mL/min per $1.73 \mathrm{~m} 2$ ), both genders, less than 70 years, and desired to participate freely in the study. The exclusion criteria were; pregnancy, end-stage renal or liver disease, , and failing to complete the online questionnaire. A total of 58 sample completed an online questionnaire reporting their demographic, anthropometric, biochemical features, and dietary patterns.

\subsection{Demographic features:}

Include information about sex, age, smoking, amount of meals /day.

\subsection{Anthropometric and biochemical Evaluation:}

Patients were asked to record information about: anthropometric data (weight, height); marker of CKD biochemical data [glomerular filtration rate (GFR), serum creatinine, albumin-to-creatinine ratio (ACR)]; and clinical data (comorbidities associated with CKD hypertension, diabetes, cardiovascular diseases) from hospital patient's recent medical records.

\subsection{Dietary patterns:}

Online food-frequency questionnaire (FFQ) with 78-food items was administered to appraise the usual food intake. The FFQ was a modified version of the NHANES Food Frequency Questionnaire (FFQ) (5). The food frequency questionnaire was validated for the Saudi population. Participants were asked to indicate how often, on average, they had consumed a given amount of the specified food. Each such item provided nine possible responses, ranging from "never or less than once a month" to "6 -7 times per day".

\subsection{Statistical analysis:}

2.5.1. Anthropometric and biochemical variable: continuous variables are presented as means \pm SD. Categorical variables are presented as frequencies..

2.5.2. Dietary patterns: were obtained by exploratory factor analysis of the eight food groups. An orthogonal rotation procedure was used which results in uncorrelated factors. Number of extracted factors was first based on the Kaiser criterion, namely eigenvalues $>1.0$. In interpreting the rotated factor pattern, a selected food was considered to load on a given factor if the factor loading was $\geq 0.30$ for that factor and $<0.30$ for all other factors. No food item was permitted to load more than one factor. The observed Kaiser-Meyer-Olkin (KMO) was 0.786 and Bartlett Test of Sphericity (BTS) is significant<.001, which meant that the sample was considered to be adequate for factor analysis.

The correlation between dietary patterns factors and the metabolic risk factors of CKD were tested with linear regression model. The predictive accuracy of linear regression model is measured by R. In multivariate models, trend for BMI, gender and age across each dietary pattern were adjusted. The selection of confounders was based on prior consideration of their associations with risk of CKD.

\section{Results:}

3.1. Demographic, Clinical and Anthropometric Findings:

Table (1) presents Characteristics of the study subjects 
Table1: Characteristics of study subjects

\begin{tabular}{|c|c|c|}
\hline Parameter & Variable & Response \\
\hline \multirow[t]{2}{*}{ Gender \% } & Male & $34(58.62 \%)$ \\
\hline & Female & $24(41.38 \%)$ \\
\hline \multirow{3}{*}{$\begin{array}{l}\text { Age/ years } \\
\text { Mean }\end{array}$} & Male & $(57.20 \pm 9.45)$ \\
\hline & Female & $(54.16 \pm 10.42)$ \\
\hline & All & $(55.62 \pm 9.73)$ \\
\hline \multirow[t]{4}{*}{ Body Mass Index (BMI) kg m2 } & $<18.5$ & $28(48.28 \%)$ \\
\hline & $18.5-25$ & $27(46.55 \%)$ \\
\hline & $>25-<30$ & $(3(5.17 \%)$ \\
\hline & Mean $(<18.5-<30)$ & $22.32 \pm 10.70$ \\
\hline \multirow[t]{2}{*}{ Smoking } & Yes & $17(29.31 \%)$ \\
\hline & No & $41(70.69 \%)$ \\
\hline \multirow[t]{4}{*}{ number of meals /day } & Once/day & (0.00\%) \\
\hline & $2-3$ meals/day & $23(29.31 \%)$ \\
\hline & 4-5 meals/day & $34(29.31 \%)$ \\
\hline & 6-7 meals/day & $1(29.31 \%)$ \\
\hline \multirow[t]{4}{*}{ Co-morbidities } & Hypertension & $21(36.21 \%)$ \\
\hline & Diabetes & $16(27.59 \%)$ \\
\hline & Cardiovascular diseases & $13(22.41 \%)$ \\
\hline & Diabetes \&Cardiovascular diseases & $8(13.79 \%)$ \\
\hline
\end{tabular}

\subsection{Biochemical Parameters of CKD Findings:}

Table (2) presents biochemical parameters of CKD of the study subjects

Table 2: Biochemical Parameters of CKD Participants

\begin{tabular}{|c|c|c|c|}
\hline Parameter & Sex & mean & No \\
\hline \multirow{2}{*}{$\begin{array}{l}\text { glomerular filtration rate (GFR): } \\
\mathrm{mL} / \mathrm{min} / 1,73 \mathrm{~m}^{2}\end{array}$} & G3a & $51.5 \pm 12.71$ & 37 \\
\hline & G3b & $34.2 \pm 19.31$ & 21 \\
\hline \multirow{3}{*}{ Serum creatinine: $\mathrm{mg} / \mathrm{dL}$} & All & $2.45 \pm \mathrm{mg} / \mathrm{dL}$ & 58 \\
\hline & male & $2.89 \pm \mathrm{mg} / \mathrm{dL}$ & 34 \\
\hline & female & $1.97 \pm \mathrm{mg} / \mathrm{dL}$ & 24 \\
\hline \multirow{3}{*}{$\begin{array}{l}\text { albumin/creatinine } \\
\text { (ACR):mg/g }\end{array}$} & All & $75.21 \pm \mathrm{mg} / \mathrm{g}$ & 58 \\
\hline & male & $75.6 \pm \mathrm{mg} / \mathrm{g}$ & 34 \\
\hline & female & $74.5 \pm \mathrm{mg} / \mathrm{g}$ & 24 \\
\hline
\end{tabular}

\subsection{Dietary Components:}

Four components were extracted through factor analysis, based on the Kaiser criterion and the scree plot (Figure 1). These four components accounted for $54.06 \%$ of the variability within the sample. The factor loading matrix for the major dietary patterns identified among sample surveyed are shown in (Table3). The first pattern, which accounted for $24.01 \%$ of the total variance, had high loadings on cucumber, zucchini, , carrots, apple, pineapple green beans, pepper (green), cauliflower, purslane, parsley, broccoli, peas, pear, red grape cabbage, pumpkin radishes, onion. Since this factor was characterized by the intake of vegetables, fruits, it was denoted" Veggie dietary pattern". The second factor explained $15.16 \%$ of the total variance. The high-loading foods on the second pattern were loadings on carbohydrates products (Pasta, Breakfast cereal, white rice, white bread, sweet potatoes, brown rice, biscuit; nuts and some legumes: almonds, cashew, pistachios, walnuts, chickpeas, tomatoes) This pattern was denoted " Plant-based dietary pattern". The third factor accounted for approximately $8.28 \%$ of the total variance. The high-loading foods on the third pattern were milk and milk products, Chicken without skin, Fish, Olive oil, oil (corn Palm. etc.). This pattern was labeled "Miscellanies pattern". The fourth pattern, denoted the " Animal-based dietary pattern ", was characterized by high loadings with meat and meat products, chickens with skin, egg and lentils. This pattern accounted for approximately $6.61 \%$ of the total variance. 


\section{Scree Plot}

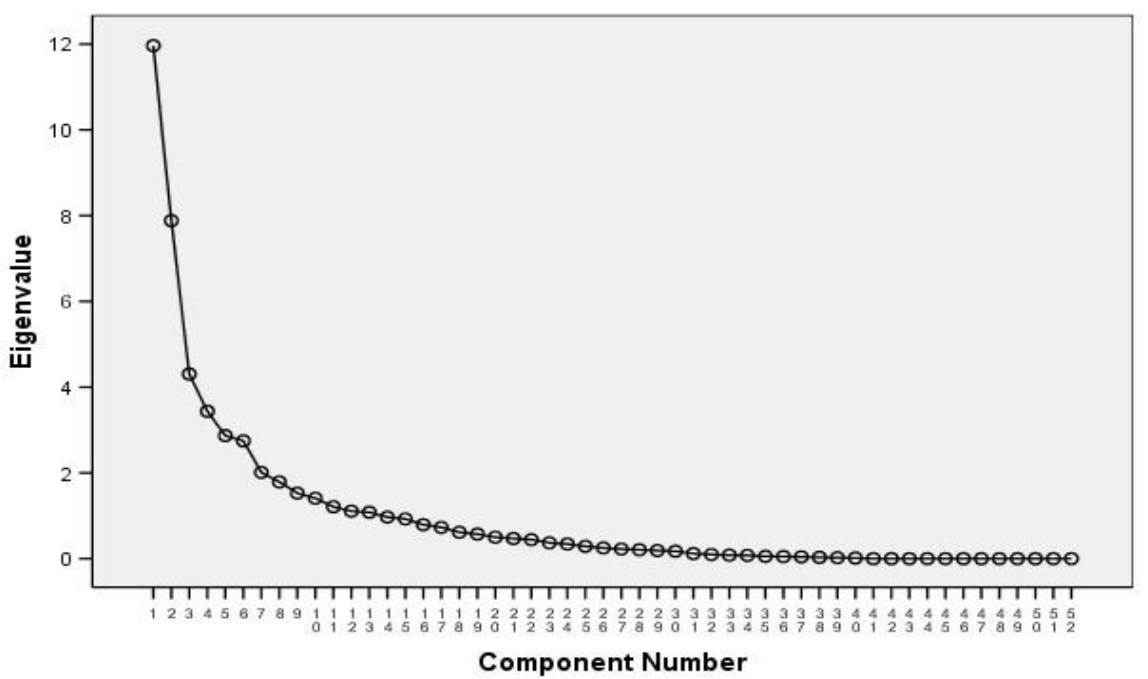

Figure 1: Scree plot of eigenvalue for each component in factor extraction of Food frequency Intake

Table 3: Food Groups with High Factor Loadings for the Four Dietary Patterns

\begin{tabular}{|c|c|c|c|c|c|c|c|}
\hline \multicolumn{2}{|c|}{$\begin{array}{l}\text { First component } \\
\text { "Veggie dietary pattern" }\end{array}$} & \multicolumn{2}{|c|}{$\begin{array}{l}\text { Second component } \\
\text { "plant-based dietary } \\
\text { pattern }\end{array}$} & \multicolumn{2}{|c|}{$\begin{array}{l}\text { Third component } \\
\text { "Miscellanies pattern" }\end{array}$} & \multicolumn{2}{|c|}{$\begin{array}{l}\text { Fourth component } \\
\text { Animal-based dietary } \\
\text { pattern" }\end{array}$} \\
\hline cucumber & .951 & Potatoes & .889 & low fat cheese & .801 & Lamb & .601 \\
\hline Zucchini & .916 & $\begin{array}{l}\text { Pasta } \\
\text { (macaroni) }\end{array}$ & .861 & low fat yogurt & .756 & Beef & .548 \\
\hline Carrots & .905 & $\begin{array}{l}\text { Breakfast } \\
\text { cereal }\end{array}$ & .857 & Low fat milk & .732 & Meat organ & .494 \\
\hline Apple & .903 & Rice( white) & .802 & Labnah & .709 & Processed meat & .437 \\
\hline Pineapple & .845 & White bread & .787 & low fat cheese & .648 & $\begin{array}{l}\text { Chicken with } \\
\text { skin }\end{array}$ & .356 \\
\hline pear & .826 & $\begin{array}{l}\text { Sweet } \\
\text { Potatoes }\end{array}$ & .770 & $\begin{array}{l}\text { Chicken } \\
\text { without skin }\end{array}$ & .595 & egg & .411 \\
\hline Green beans & .816 & Rice(brown) & .679 & $\begin{array}{l}\text { Fish } \\
\text { products) }\end{array}$ & .560 & Lentils & .342 \\
\hline Pepper (green) & .781 & Biscuit & .666 & Olive oil & .482 & Beans & .311 \\
\hline cauliflower & .751 & Brown bread & .582 & $\begin{array}{l}\text { oil (corn } \\
\text { Palm.. etc. }\end{array}$ & .461 & & \\
\hline Purslane & .666 & Chickpeas & .545 & $\begin{array}{l}\text { whole fat } \\
\text { cheese }\end{array}$ & .431 & & \\
\hline Parsley & .651 & Almonds & .524 & & & & \\
\hline Broccoli & .650 & Cashew & .501 & & & & \\
\hline peas & .543 & Pistachios & .499 & & & & \\
\hline Red grapes & .506 & Walnuts & .441 & & & & \\
\hline pumpkin & .502 & Cake & .387 & & & & \\
\hline Cabbage & .501 & & & & & & \\
\hline radishes & .498 & & & & & & \\
\hline Onions & .435 & & & & & & \\
\hline $\begin{array}{l}\text { Initial } \\
\text { Eigenvalues }\end{array}$ & 11.91 & & 7.88 & & 4.31 & & 3.44 \\
\hline$\%$ of Variance & 24.01 & & 15.16 & & 8.28 & & 6.61 \\
\hline Cumulative $\%$ & 24.01 & & 39.17 & & 47.45 & & 54.06 \\
\hline $\begin{array}{l}\text { Frequency of } \\
\text { factor } \%\end{array}$ & 34.61 & & 28.85 & & 21.16 & & 15.38 \\
\hline
\end{tabular}

Extraction Method: Principal Component Analysis.

Rotation Method: Promax with Kaiser Normalization. 


\subsection{Associations of Factor Analysis-Derived Pattern Scores with Risk Factors of CKD:}

The associations of food pattern with metabolic risk factors of CKD as well as adjusted correlation of dietary patterns with glomerular filtration rate (GFR), serum creatinine, albumin-to-creatinine ratio (ACR) among subjects surveyed are shown in Table (4) and Table (5).

Table 4: Association between Dietary patterns and Biochemical Factors of CKD among Samples Surveyed

\begin{tabular}{|c|c|c|c|c|c|c|c|c|}
\hline \multirow[t]{3}{*}{ Variable } & \multicolumn{4}{|c|}{ glomerular filtration rate } & \multirow{2}{*}{\multicolumn{2}{|c|}{$\begin{array}{l}\text { Serum } \\
\text { creatinine }\end{array}$}} & \multirow{2}{*}{\multicolumn{2}{|c|}{$\begin{array}{l}\text { albumin/creatinine } \\
\text { ratio }\end{array}$}} \\
\hline & \multicolumn{2}{|l|}{$\mathrm{G} 3 \mathrm{a}$} & \multicolumn{2}{|l|}{$\mathrm{G} 3 \mathrm{~b}$} & & & & \\
\hline & $r$ & P-value & $r$ & P-value & $r$ & P-value & $r$ & P-value \\
\hline Veggie dietary pattern & -0.591 & .008 & -0574 & .015 & -.607 & .007 & -0.601 & .007 \\
\hline Plant-based dietary pattern & .486 & .061 & .488 & .060 & .508 & .051 & .509 & .051 \\
\hline Miscellanies pattern & -.489 & .058 & -.481 & .061 & -.524 & .040 & -.528 & .04 \\
\hline Animal-based dietary pattern & .557 & .021 & .551 & .023 & .661 & .001 & .660 & .001 \\
\hline
\end{tabular}

Food group analysis showed that " Veggie dietary pattern " was inversely correlated with the metabolic risk factors of CKD ( $p$ values range .007 - .031). Adjustment for BMI, gender and age did not substantially change the associations. Analysis showed that "Animal-based dietary pattern" was positively correlated with the metabolic risk factors of CKD ( $p$ values range.001 - .023). Adjustment for BMI, gender and age did not substantially change the associations. Thus, " Animal-based dietary pattern " remains independent predictor of CKD risk factors.

The " plant-based dietary pattern" was no longer associated with glomerular filtration rate, but positively correlated with serum creatinine and albumin/creatinine ratio, however, marginally insignificant.

The "Miscellanies pattern" was no longer associated with glomerular filtration rate, but inversely correlated with serum creatinine and albumin/creatinine ratio.

The " Plant-based dietary pattern" and "Miscellanies pattern" were no longer associated with the metabolic risk factors of CKD after adjustment for BMI, gender and age.

Table 5: Multivariate adjusted Correlation of Dietary patterns with Biochemical Factors of CKD among Samples Surveyed

\begin{tabular}{|c|c|c|c|c|c|c|c|c|}
\hline \multirow{3}{*}{ Variable } & \multicolumn{4}{|c|}{ Glomerular filtration rate } & \multirow{2}{*}{\multicolumn{2}{|c|}{ Serum creatinine }} & \multirow{2}{*}{\multicolumn{2}{|c|}{$\begin{array}{l}\text { Albumin/creatinine } \\
\text { ratio }\end{array}$}} \\
\hline & \multicolumn{2}{|l|}{ G3a } & \multicolumn{2}{|c|}{$\mathrm{G} 3 \mathrm{~b}$} & & & & \\
\hline & $\boldsymbol{r}$ & P-value & $r$ & P-value & $\boldsymbol{r}$ & P-value & $r$ & P-value \\
\hline \multicolumn{9}{|c|}{ Veggie dietary pattern } \\
\hline $\begin{array}{l}\text { Model 1 } \\
\text { (unadjusted) }\end{array}$ & -591. & .008 & -.574 & .015 & -.607 & .007 & -.601 & .007 \\
\hline Model 2† & -.590 & .008 & -.570 & .015 & -.606 & .007 & -.598 & .008 \\
\hline Model 3t & -.566 & .020 & -.551 & .023 & -.601 & .007 & -.598 & .008 \\
\hline Model4 $\neq$ & -.548 & .023 & -.541 & .031 & -.596 & .008 & -.581 & .010 \\
\hline \multicolumn{9}{|c|}{ Plant-based dietary pattern } \\
\hline $\begin{array}{l}\text { Model } 1 \\
\text { (unadjusted) }\end{array}$ & .486 & .061 & .488 & .060 & .508 & .051 & .509 & .051 \\
\hline Model 2† & .480 & .062 & .481 & .062 & .498 & .057 & .491 & .057 \\
\hline Model 3† & .479 & .062 & .484 & .060 & .490 & .057 & .481 & .062 \\
\hline Model4ł & .474 & .063 & .473 & .063 & .483 & .060 & .480 & .061 \\
\hline \multicolumn{9}{|c|}{ Miscellanies pattern } \\
\hline $\begin{array}{l}\text { Model 1 } \\
\text { (unadjusted) }\end{array}$ & -.489 & .058 & -.481 & .061 & -.524 & .040 & -.528 & .04 \\
\hline Model 2† & -.474 & .063 & -.479 & .061 & -.503 & .056 & -.504 & .056 \\
\hline Model 3t & -.472 & .063 & -.477 & .061 & -.503 & .056 & -.503 & .056 \\
\hline Model4 $\ddagger$ & -.469 & .064 & -.468 & .062 & -.501 & .056 & -.505 & .054 \\
\hline \multicolumn{9}{|c|}{ Animal-based dietary pattern } \\
\hline $\begin{array}{l}\text { Model } 1 \\
\text { (unadjusted) }\end{array}$ & .557 & .021 & .551 & .023 & .661 & .001 & .660 & .001 \\
\hline Model $2 \dagger$ & .554 & .022 & .552 & .023 & .655 & .002 & .646 & .005 \\
\hline Model 3t & .554 & .022 & .550 & .023 & .638 & .006 & .640 & .006 \\
\hline Model4 $\neq$ & .550 & .023 & .550 & .023 & .631 & .006 & .630 & .006 \\
\hline
\end{tabular}

$\uparrow$ Adjusted by BMI

+ Adjusted by gender

$\neq$ Adjusted by age (years), 


\section{Discussion:}

CKD is defined as abnormalities of kidney structure or function, with health consequences. Saudi population is experiencing changes in their dietary habits in the last two decades with accompanying increase in chronic diseases rate including CKD. Dietary modifications may play an important role in the etiology and progression of CKD. The main objective of this study is to identify dietary pattern in chronic kidney disease of Saudi out patients' participants and to determine the correlation between dietary patterns identified and metabolic risk factors i.e. GFR, serum creatnine and albumin/creatinine ratio.

Four dietary patterns: "Veggie dietary pattern", "Plant-based dietary pattern", "Miscellanies pattern" and " Animal-based dietary pattern were identified (Table 3). Subjects who followed the " Animal-based dietary pattern "were found to have a risk of biomarkers of CKD. In contrast, the "Veggie dietary pattern" was inversely associated with risks of CKD. Meanwhile, both the "plant-based dietary pattern" and "Miscellanies pattern" were marginally either positively or inversely associated with metabolic risk factors of CKD.

Veggie dietary pattern of this study was characterized by higher consumption of vegetables and fruits. Previous research suggests that increased vegetable intake could lead to a decrease in risk of CKD and mortality (6). In the Multiethnic Study of Atherosclerosis, dietary patterns characterized by consumption of fruits and vegetables were associated with lower albumin/creatinine ratio (7). Purslane was One of component of the "Veggie dietary pattern " of the present study. Results of Ghara and Ghadi (8) study showed that purslane administration decreased the elevated level of creatinine and BUN in rats. This study revealed that purslane improved some kidney function parameters due to its antioxidant and antiinflammatory properties.

Chauveau and Lasseur (9). stated that higher consumption of fruits and vegetables is associated with less inflammation and oxidative stress. Nettleton et.al. (7). reported that diets high in whole grains, fruits or vegetables, and fish are inversely associated with markers of inflammation including C-reactive protein (CRP) whereas a diet pattern high in fats and processed meats was directly associated with markers of inflammation including CRP. Kshirsagar et.al. (10) indicated that inflammation might be one possible pathophysiologic link between dietary patterns and microalbuminuria. A large, nationally representative data set showed association of serum C-reactive protein (CRP), with microalbuminuria, a marker of early kidney injury and concluding that elevated levels of serum C-reactive protein (CRP), may play a role in kidney disease. Elevated CRP levels are associated with micro/macroalbuminuria independent of diabetes, hypertension and other potential confounders. This suggests that inflammation may play a role in early kidney damage (11). Animal-based dietary pattern identified by the present study was characterized with meat and meat products, chickens with skin, egg and lentils. The positive association with meat consumption with CKD's risk factors in this study (Table 4) is consistent with similar patterns in several other studies. Bernstein et.al. (12). stated that animal protein causes dynamic effects on renal function. The finding of a study of Nettletonet.al. (7) showed that a dietary pattern with lower red meat and carbohydrates content was associated with lower risks of kidney failure. In a Cochrane review of low protein diets among people with CKD, a delay in progression of CKD was observed with a low protein intake (13). A dietary pattern consisting mostly of processed and fried foods, organ meats, and sweets has been found to be associated with an increased risk of mortality in patients with CKD (14). Lew et.al. (15) stated that red meat intake strongly associated with ESRD risk. Study of Harig, et al. (16) found that there was varied associations of specific dietary protein sources with risk of incident CKD with red and processed meat being adversely associated with CKD risk.

Metabolic studies tend to suggest positive associations between higher consumption of acid foods and risk of CKD. Published data have shown that red meat generally yields greater acid production than other animal-sourced protein (17). Lower daily acid load is associated with better control of acidosis. Dietary acid is thought to promote the progression of CKD; a higher dietary acid load can cause metabolic acidosis and lead to increased risk for kidney disease progression (18). Thus, a dietary balance between acid-producing (e.g., animal sources of protein) and base-producing (e.g., vegetables and fruit) foods is important. High dietary acid load has been shown to be associated with higher incidence of ESRD in the general population in the United States (17). Conversely, plant-based proteins (e.g., soy and legumes) and fruits and vegetables have a high basal load (19).

Miscellanies pattern of this study was characterized by higher consumption of low-fat dairy products (Table 3). Previous research suggests that dairy products may decrease the risk of CKD. Results of study carried by Bernstein et.al. (12) showed that intakes of dairy products, particularly low-fat dairy, had an inverse association with CKD. In Study of Atherosclerosis, dietary patterns characterized by consumption of low-fat dairy were associated with lower albumin/creatinine ratio (7). Study of Lew et.al. (15) showed that intake of poultry, fish, eggs, dairy products did not associate with risk of ESRD. Findings of study of Haring et.al. (16) showed that there was varied associations of specific dietary protein sources with risk of incident CKD; nuts, and low-fat dairy products, and legumes being protective against the development of CKD. Evidence has suggested that protein from dairy may be less detrimental to renal health than protein from nondairy products. These associations were partially explained by dietary components of dairy (monounsaturated fat, polyunsaturated fat, phosphorus, magnesium, calcium, and vitamin D. (20).

Plant-based dietary pattern identified by the present study was characterized by increasing consumption of calorie-dense foods containing whole and refined carbohydrates, and nuts. This study reveals a positive association but insignificant of Plant-based pattern with CKD's risk factors. It is thought that diets high in refined starches, saturated fats, sodium, and lower in whole grains, fruit, vegetables, and fiber may heighten the inflammatory response (21). Elevations in inflammatory markers have been suggested as a biomarker for the incidence of CKD (22). Williams et.al. (23) stated that organizations such as the National Kidney Foundation, the American Kidney Fund, the National Institute of Diabetes and Digestive and Kidney Diseases, and the US Department of Health and Human Services recommend not including whole grains as part of the renal diet. This due to the high phosphorus content in these foods. The positive association, however 
insignificant with grains consumption with CKD's risk factors in this study seem inconsistent with similar patterns in several other studies. Dietary patterns characterized by consumption of whole grains, fruits and vegetables were associated with lower albumin/creatinine ratio (7). Bach et.al. (24) stated that a healthy dietary pattern (higher intakes of vegetables, fruit, legumes, nuts, whole grains, fish and low-fat dairy) may prevent CKD and albuminuria.

\section{Conclusions:}

The present study revealed that Animal-based dietary pattern were found to have a risk of biomarkers of CKD. In contrast, the "Veggie dietary pattern" was inversely associated with risks of CKD.

\section{Recommendations:}

Since Saudi people are facing a rapid nutritional and lifestyle transition accompanied by an increase in chronic kidney disease, it appears conceivable that the risk of developing CKD and its complications can be reduced by changing dietary patterns.

\section{Acknowledgments:}

The author would like to thank study participants for their cooperation in this study.

\section{References:}

[1].Hill NR, Fatoba ST, Oke JL, Hirst JA, O’Callaghan C A, Lasserson D S, and Richard Hobbs F D. Global Prevalence of Chronic Kidney Disease - A Systematic Review and MetaAnalysis, PLoS One. 2016; 11(7): e0158765.

[2].Al Sayyari, A.A., and Shaheen, F.A. (M 2011), End stage chronic kidney disease in Saudi Arabia 2011, Saudi medical journal 32(4):339-46,

[3].United States Department of Agriculture Scientific report of the Dietary Guidelines Advisory Committee. Available at: $\quad$ https://health.gov/dietaryguidelines/2015-scientificreport/PDFs/Scientific-Report-of-the-2015-DietaryGuidelines-Advisory-Committee.pdf. Accessed 22 November 2016.

[4].Ahmed HG, Alzayed FSM, Albluwe H K A, Alosayfir Z A S, Aljarallah M Y J, Alghazi B K . and Alshammari MAG. Etiology of Chronic Kidney Disease (CKD) in Saudi Arabia, International Journal of Medical Research \& Health Sciences, 2019; 8(5): 177-182.

[5].National Health and Nutrition Examination Survey (NHANES), 2018; https://epi.grants.cancer.gov/diet/usualintakes/FFQ.English.June0304.

[6].Dunkler D, Kohl M, Teo KK. Population-attributable fractions of modifiable lifestyle factors for CKD and mortality in individuals with type 2 diabetes: a cohort study. Am J Kidney Dis. 2016;68:29-40.

[7].Nettleton JA, Steffen LM, Palmas W, Burke GL, Jacobs DR. Associations between microalbuminuria and animal foods, plant foods, and dietary patterns in the Multiethnic Study of Atherosclerosis. Am. J. Clin. Nutr. 2008;87:18251836. doi: 10.1093/ajcn/87.6.1825.

[8].Ghara AR, Ghadi FE. (2018), Effect of Purslane on Kidney Failure Following Copper Toxicity in A Rat Model,2018; 6(1): 25-32.

[9].Chauveau P, and Lasseur C. Plant-based Protein Intake and Kidney Function in Diabetic Patients. Kidney International Report. 2019; 4(5): 638-639.

[10]. Kshirsagar AV, Bomback AS, Bang H, Gerber LM, Vupputuri S, Shoham DA, Mazumdar M, Ballantyne CM, Paparello JJ, Klemmer PJ. Association of C-reactive protein and microalbuminuria (from the National Health and Nutrition Examination Surveys, 1999 to 2004) Am. J. Cardiol. 2008;101(3):401-406.

[11]. Sabanayagam C, Lee J, Shankar A, Lim SC, Wong TY, Tai ES. C-reactive protein and microalbuminuria in a multiethnic Asian population. Nephrol. Dial. Transplant.2010; 25(4):1167-72.

[12]. Bernstein AM, Treyzon L, Li Z. Are high-protein, vegetable-based diets safe for kidney function? A review of the literature. J Am Diet Assoc.2007;107(4):644-50.

[13]. Fouque D, Laville M. Low protein diets for chronic kidney disease in non-diabetic adults. Cochrane Database of Systematic Reviews 2009, Issue 3. [DOI: 10.1002/14651858.CD001892.pub3

[14]. Gutiérrez OM, Muntner P, Rizk DV, McClellan WM, Warnock DG, Newby PK, Judd SE. Dietary patterns and risk of death and progression to ESRD in individuals with CKD: a cohort study. Am. J. Kidney Dis. 2014; 64: $204-213$.

[15]. Lew QJ, Jafar TH, Koh HW, Jin A, Chow KY, Yuan JM, Koh WP. Red Meat Intake and Risk of ESRD. A So Nephrol. 2017;28(1):304-312.

[16]. Haring B, Selvin E, Liang M, Coresh J, Grams ME, Petruski-Ivleva N, Steffen LM, Rebholz CM· (2017) Dietary Protein Sources and Risk for Incident Chronic Kidney Disease: Results From the Atherosclerosis Risk in Communities (ARIC) Study. J Ren Nutr.2017;27(4):233-242.

[17]. Banerjee T, Crews DC, Wesson DE, Tilea AM, Saran R, Ríos-Burrows N, Williams DE, Powe NR. Centers for Disease Control and Prevention Chronic Kidney Disease Surveillance Team, High Dietary Acid Load Predicts ESRD among Adults with CKD. J. Am. Soc. Nephrol. 2105; 26: 1693-1700.

[18]. Jhee J H, Kee YK, Park JT, Chang T, Kang E W, Yoo T, Kang S, Han SH. Diet high in vegetables and fruit may help prevent CKD, Am J Kidney Dis. 2019; 74 ( 4): 491-500.

[19]. Scialla JJ, Anderson CA.Dietary acid load: a novel nutritional target in chronic kidney disease? Adv. Chronic Kidney Dis.2013;20: 141-149. 
[20]. Herber-Gast GM, Biesbroek S, Verschuren WM, Stehouwer CD, Gansevoort RT, Bakker SJ, Spijkerman AM. Association of dietary protein and dairy intakes and change in renal function: results from the population-based longitudinal Doetinchem cohort study. Am J Clin. Nutr. 2016;104(6):1712-1719.

[21]. Casasm R, Estruch R. Dietary patterns, foods, nutrients and chronic inflammatory disorders. Immunome. Res. 2016; 12: 122, 2016.

[22]. Fried L, Solomon C, Shlipak M, Seliger S, Stehman-Breen C, Bleyer AJ, Chaves P, Furberg C, Kuller L, Newman A,. Inflammatory and prothrombotic markers and the progression of renal disease in elderly individuals. J Am Soc Nephrol. 2004; 15: 3184-3191.

[23]. Williams C, Roncom C, Kotanko P. Whole Grains in the Renal Diet - Is It Time to Reevaluate Their Role? Blood Purif 2013; 36:210-214.

[24]. Bach KE, Kelly JT, Palmer SC, Khalesi S, Strippoli GFM, Campbell KL. Healthy Dietary Patterns and Incidence of CKD: A Meta-Analysis of Cohort Studies. Clin J Am Soc Nephrol. 2019;14(10):1441-1449. 